\title{
Design and Analysis of TIDF controller in AGC with Thyristor Controlled series capacitor
}

\author{
Sarada Prasanna Behera ${ }^{1}$, Ashutosh Biswal ${ }^{2}$ \\ PG scholar, Dept of Electrical Engg., Indira Gandhi Institute of Technology, Sarang, Odisha, India ${ }^{1}$ \\ Assistant Professor (consolidated), Dept of Electrical Engg., IGIT, Sarang, Odisha, India ${ }^{2}$
}

\begin{abstract}
This paper proposes an automatic generation control (AGC) of an interconnected two area of non-reheat thermal power system in continuous mode by employing a Thyristor Controlled Series Capacitor (TCSC) connected in series with the line. By controlling the reactance of the TCSC the damping of the system frequency and tie line power oscillations are minimize. Differential Evolution (DE) algorithm has been used for optimization of different parameters. The performance of the Tilted integral derivative controller with Filter (TIDF) without TCSC has been evaluated and the result is compared with TIDF controller without TCSC and TIDF controller with TCSC. Investigations reveal that TIDF controller with TCSC provides better dynamics than TIDF controller without TCSC. It is reported that ITAE criterion improving the peak overshoot as wall as it reduces the peak undershoot of the system.
\end{abstract}

Keywords: Automatic generation control (AGC), Tilted integral derivative controller with Filter (TIDF), Integral Time multiplies Absolute Error (ITAE), Differential Evolution (DE), Thyristor Controlled Series Capacitor (TCSC).

\section{INTRODUCTION}

An electrical power systems means, it is the between control areas. If there is small change in load interconnection of more than one control areas, in which power in a single area power system operating at set value the generators are always vary their speed (slow down or of frequency then it creates mismatch in power both for speed up) for maintenance of reactive power angles and generation and demand. So AGC is a system which can be the frequency to the predefined values in both of the static use for adjusting the power output of multiple generators and dynamic conditions. If there is any sudden load at different power plants, in response to changes on the change occurs in any control area of an interconnected load, since the power grid requires that generation and power system then there will be change in frequency as load closely balance moment by moment, frequency well as tie-line power deviation occurs. So it is essential to adjustments to the output of the generators are necessary maintain the frequency and inter area tie line power nearer because the load variation in the power system is to the scheduled values.

unpredictable

The mechanical power given as input is used not only to control the frequency of generators but also to sense the change in the frequency and tie line power, which is a measure of the change in rotor angle. Due to this a well designed power system is essential which provide the acceptable levels of power quality by keeping the frequency and voltage magnitude within its tolerable limits. If any changes occur in the power system load mainly affects the system frequency, while the reactive power is less sensitive to changes in frequency and it is mainly dependent on the fluctuations of the voltage magnitude. So due to this the real and reactive power control in the power system should be dealt separately in the power system. The system frequency and real power control is dealt by load frequency control where as the regulation in the changes in reactive power and voltage magnitude is dealt by the automatic voltage regulator loop [1-3]. The main objective of load frequency control (LFC) are to maintain the real frequency and the desired power output (megawatt) in the interconnected power system and the other one is to control the change in tie line power

So a high frequency deviation can lead to a system collapse. This gives rise to the necessity that an accurate and fast acting controller is to be maintained for a constant nominal frequency. This gives rise to the necessity that an accurate and fast acting controller is to be maintained for a constant nominal frequency. So, the most effective counter measure that can be considered are the fast acting energy storage devices. However, it may not be economically feasible to use these devices in every area of a multi-area interconnected power system as it increases the overall cost of the system. So in order to enhance the controllability and the power transfer capability, High Voltage AC transmission systems based on power electronic and other static controllers are used. These devices are termed as Flexible AC Transmission System (FACTS) Devices [4]. Out of the many other FACTS series devices, one of the major FACTS devices is Thyristor Controlled Series Capacitor (TCSC) used for frequency stabilization by locating TCSC in series with the tie-line between interconnected two-area power systems. 
Vol. 5, Issue 3, March 2017

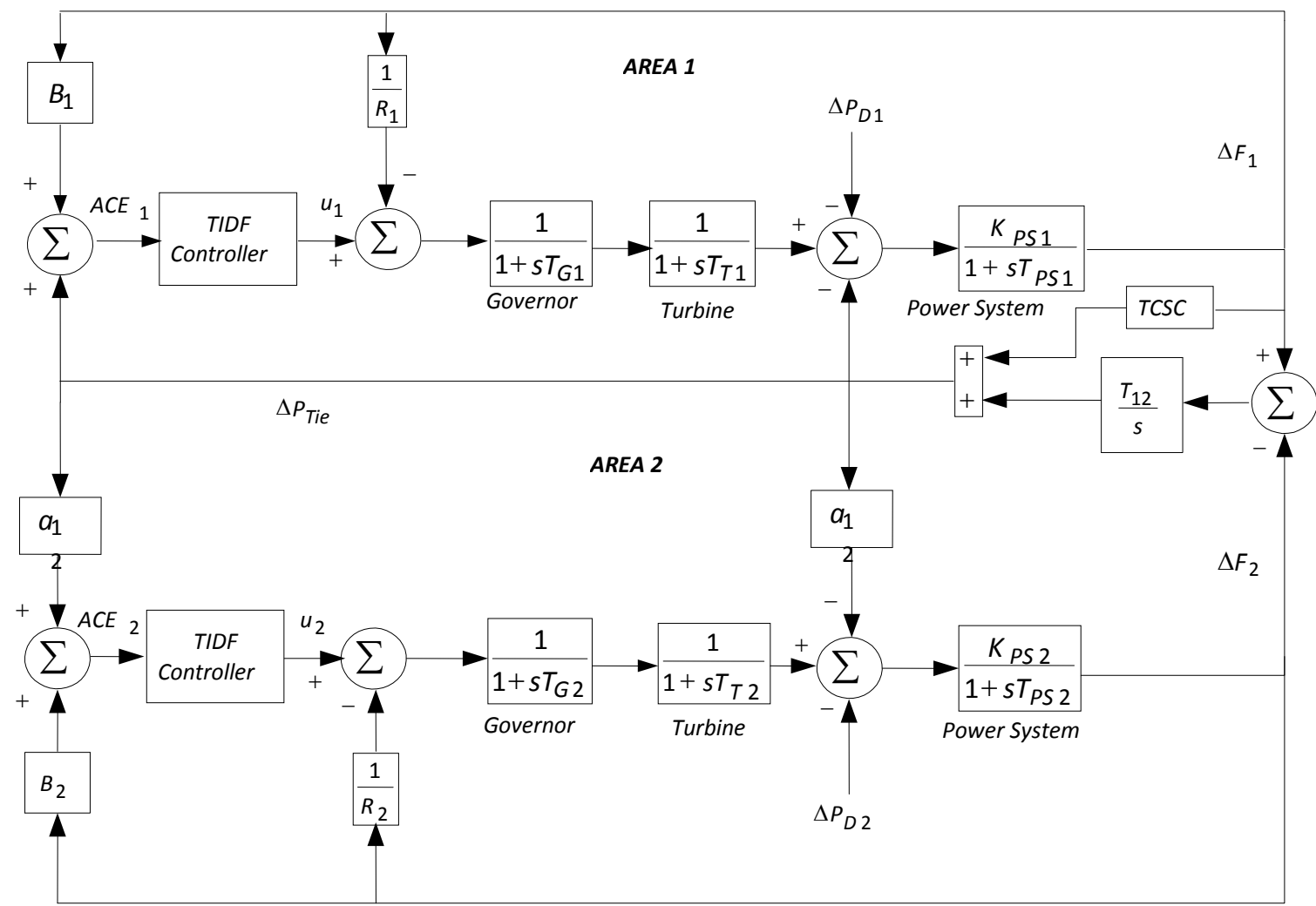

Fig.1 MATLAB/SIMULINK model of two-area non reheat thermal interconnected power system with TCSC

In this paper an attempt has taken to improve the flow in between these areas. So areas affects each other, performance of AGC-TCSC combination with Tilted that is, any changes in load in one of the areas affects the integral derivative controller with filter (TIDF). In the output frequencies of other areas as well as the tie-line present study, Differential Evolution (DE) algorithm is power.

proposed for optimized gains of Tilted integral derivative In order to bring the local frequency to its steady state controller with filter (TIDF) and the performance of the value the control system of each area needs detailed Tilted integral derivative controller with Filter (TIDF) information about the transient situation in all the other without TCSC has been evaluated and the result is areas. Since governor alone does not have the capability to compared with TIDF controller with TCSC. Investigations provide adequate control of frequency, so to damp the reveal that TIDF controller with TCSC provides better frequency we use a Thyristor Controlled Series Capacitor dynamics than TIDF controller without TCSC. The power (TCSC) in series with the tie-line. The above statement system with two areas having two non reheat steam can be verified in Fig.1 which shows the complete block turbines is considered in simulation study. The model of diagram of an interconnected two-area non-reheat power the system under study has been developed in system.

MATLAB/SIMULINK environment. In the simulation, firstly, a step load increase in the first area of the power system, then a step load increase in the second area of the power system and then step load increases in both areas of the same power system are considered.

\section{MATERIALS AND METHODS}

\section{A. Power System Investigated}

In this paper consists of two non-reheat thermal power plant connected by tie-line. Each area of the power system consists of speed governing system, turbine and generator as shown in Fig. 1 having three inputs and two outputs.

According to its respective user requirement each area supplies power and the tie-lines allow electrical power to

In Fig.1, $A C E_{1}$ and $A C E_{2}$ are area control errors; $B_{1}$ and $B_{2}$ are the frequency bias parameters; $u_{1}$ and $u_{2}$ are the control outputs from the controller; $R_{1}$ and $R_{2}$ are the governor speed regulation parameters in pu $\mathrm{Hz} ; T_{G 1}$ and $T_{G 2}$ are the speed governor time constants in sec; $T_{T 1}$ and $T_{T 2}$ are the turbine time constant in sec; $\Delta P_{D 1}$ and $\Delta P_{D 2}$ are the load demand changes; $\Delta P_{T i e}$ is the incremental change in tie line power in pu; $K_{P S 1}$ and $K_{P S 2}$ are the power system gains; $T_{P S 1}$ and $T_{P S 2}$ are the power system time constant in sec; $T_{12}$ is the synchronizing coefficient and $\Delta F_{1}$ and $\Delta F_{2}$ are the system frequency deviations in 
Vol. 5, Issue 3, March 2017

and $\Delta F_{1}$ and $\Delta F_{2}$ are the system frequency deviations in $\mathrm{Hz}$. The relevant parameters are given in appendix.

\section{B. Modeling of TCSC in LFC}

In order to enhance the controllability and the power transfer capability, High Voltage AC transmission systems based on power electronic and other static controllers are used. These devices are termed as Flexible AC Transmission System (FACTS) Devices [4]. Out of the many FACTS series devices, one of the major FACTS devices is Thyristor Controlled Series Capacitor (TCSC) used for frequency stabilization by locating TCSC in series with the tie-line between interconnected power systems. Basically a TCSC consists of capacitor banks, bypass inductor and bidirectional thyristors where the reactance of TCSC is controlled by controlling the firing angles of the thyristors in accordance with a system control algorithm, normally in response to some system parameter variations. Both capacitive and inductive reactance compensation are possible by proper selection of capacitor and inductor values of the TCSC device. TCSC is considered as a variable reactance, the value of which is adjusted automatically to constrain the power flow across the branch to a specified value. The variable reactance $\mathrm{X}_{\mathrm{TCSC}}$ represents the net equivalent reactance of the TCSC, when operating in either the inductive or the capacitive mode [5]. Fig.2 shows the schematic diagram of a two area interconnected thermal-thermal power system with TCSC connected in series with the tie-line. Since the reactance to the resistance ratio is quite high $(X / R>=10)$ the effect of the resistance in the dynamic performance investigation is neglected. The incremental tie-line power flow without TCSC is given by (1).

$$
\Delta P_{T i e 12}(s)=\frac{2 \pi T_{12}}{s}\left[\Delta F_{1}(s)-\Delta F_{2}(s)\right]
$$

In the above equation, $\Delta F_{1}$ and $\Delta F_{2}$ are the system frequency deviations; $T_{12}$ is the synchronizing coefficient without TCSC. The line current flow from area-1 to area-2 can be written as, when TCSC is connected in series with the tie-line

$$
I_{12}=\frac{\left|V_{1}\right| \angle\left(\delta_{1}\right)-\left|V_{2}\right| \angle\left(\delta_{2}\right)}{j\left(X_{12}-X_{T C S C}\right)}
$$

Where $\mathrm{X}_{12}$ and $\mathrm{X}_{\mathrm{TCSC}}$ are the tie-line and TCSC reactance respectively.

It is clear from Fig. 2 that, the complex tie-line power as

$$
\begin{aligned}
& P_{\text {Tie } 12}-j Q_{\text {Tie } 12}=V_{1}^{*} I_{12}= \\
& \left|V_{1}\right| \angle\left(-\delta_{1}\right)\left[\frac{\left|V_{1}\right| \angle\left(\delta_{1}\right)-\left|V_{2}\right| \angle\left(\delta_{2}\right)}{j\left(X_{12}-X_{T C S C}\right)}\right]
\end{aligned}
$$

Solving the above equation, the real part,

$$
P_{\text {Tie } 12}=\frac{\left|V_{1}\right|\left|V_{2}\right|}{\left(X_{12}-X_{T C S C}\right)} \sin \left(\delta_{1}-\delta_{2}\right)
$$

The tie-line power flow can be represented in terms of $\%$ compensation $\left(\mathrm{k}_{\mathrm{C}}\right)$ as

$$
P_{\text {Tie } 12}=\frac{\left|V_{1}\right|\left|V_{2}\right|}{X_{12}\left(1-k_{C}\right)} \sin \left(\delta_{1}-\delta_{2}\right)
$$

Where $k_{C}=\frac{X_{T C S C}}{X_{12}}$, percentage of compensation offered by the TCSC

Eq. (5) can be written as

$$
P_{\text {Tie } 12}=\frac{\left|V_{1}\right|\left|V_{2}\right|}{X_{12}} \sin \left(\delta_{1}-\delta_{2}\right)+\frac{k_{C}}{1-k_{C}} \frac{\left|V_{1}\right|\left|V_{2}\right|}{X_{12}} \sin \left(\delta_{1}-\delta_{2}\right)
$$

The first term in (6) explain the power flow in tie-line without the TCSC and the second term represents the presence of TCSC in the tie-line power flow. In order to obtain the linear incremental model, the equation (6) can be rewritten as:

$$
\begin{aligned}
& \Delta P_{\text {Tie } 12}=\frac{\left|V_{1}\right|\left|V_{2}\right|}{X_{12}} \cos \left(\delta_{1}^{0}-\delta_{2}^{0}\right) \sin \left(\Delta \delta_{1}-\Delta \delta_{2}\right)+ \\
& \frac{\Delta k_{C}}{1-\Delta k_{C}} \frac{\left|V_{1}\right|\left|V_{2}\right|}{X_{12}} \sin \left(\delta_{1}^{0}-\delta_{2}^{0}\right)
\end{aligned}
$$

As for a small change in real power load, the variation of load angle is practically very small, we can assume that $\sin \left(\Delta \delta_{1}-\Delta \delta_{2}\right) \approx \Delta \delta_{1}-\Delta \delta_{2}$. Therefore Eq. (7) can be written as

$$
\begin{aligned}
& \Delta P_{\text {Tie } 12}=\frac{\left|V_{1}\right|\left|V_{2}\right|}{X_{12}} \cos \left(\delta_{1}^{0}-\delta_{2}^{0}\right)\left(\Delta \delta_{1}-\Delta \delta_{2}\right)+ \\
& \frac{\Delta k_{C}}{1-\Delta k_{C}} \frac{\left|V_{1}\right|\left|V_{2}\right|}{X_{12}} \sin \left(\delta_{1}^{0}-\delta_{2}^{0}\right)
\end{aligned}
$$

The Eq. (8) reduced to

$\Delta P_{\text {Tie } 12}=T_{12}\left(\Delta \delta_{1}-\Delta \delta_{2}\right)+\frac{\Delta k_{C}}{1-\Delta k_{C}} K_{1}$

Where, $\quad T_{12}=\frac{\left|V_{1}\right|\left|V_{2}\right|}{X_{12}} \cos \left(\delta_{1}^{0}-\delta_{2}^{0}\right) \quad$ and $K_{1}=\frac{\left|V_{1}\right|\left|V_{2}\right|}{X_{12}} \sin \left(\delta_{1}^{0}-\delta_{2}^{0}\right)$

Since $\Delta \delta_{1}=2 \pi \int \Delta F_{1} d t$ and $\Delta \delta_{2}=2 \pi \int \Delta F_{2} d t$

Taking Laplace transforms of Eqn. (9) and expressed as given by (10)

$\Delta P_{T i e 12}(s)=\frac{2 \pi T_{12}}{S}\left[\Delta F_{1}(s)-\Delta F_{2}(s)\right]+\frac{\Delta k_{C}}{1-\Delta k_{C}} K_{1}$ 


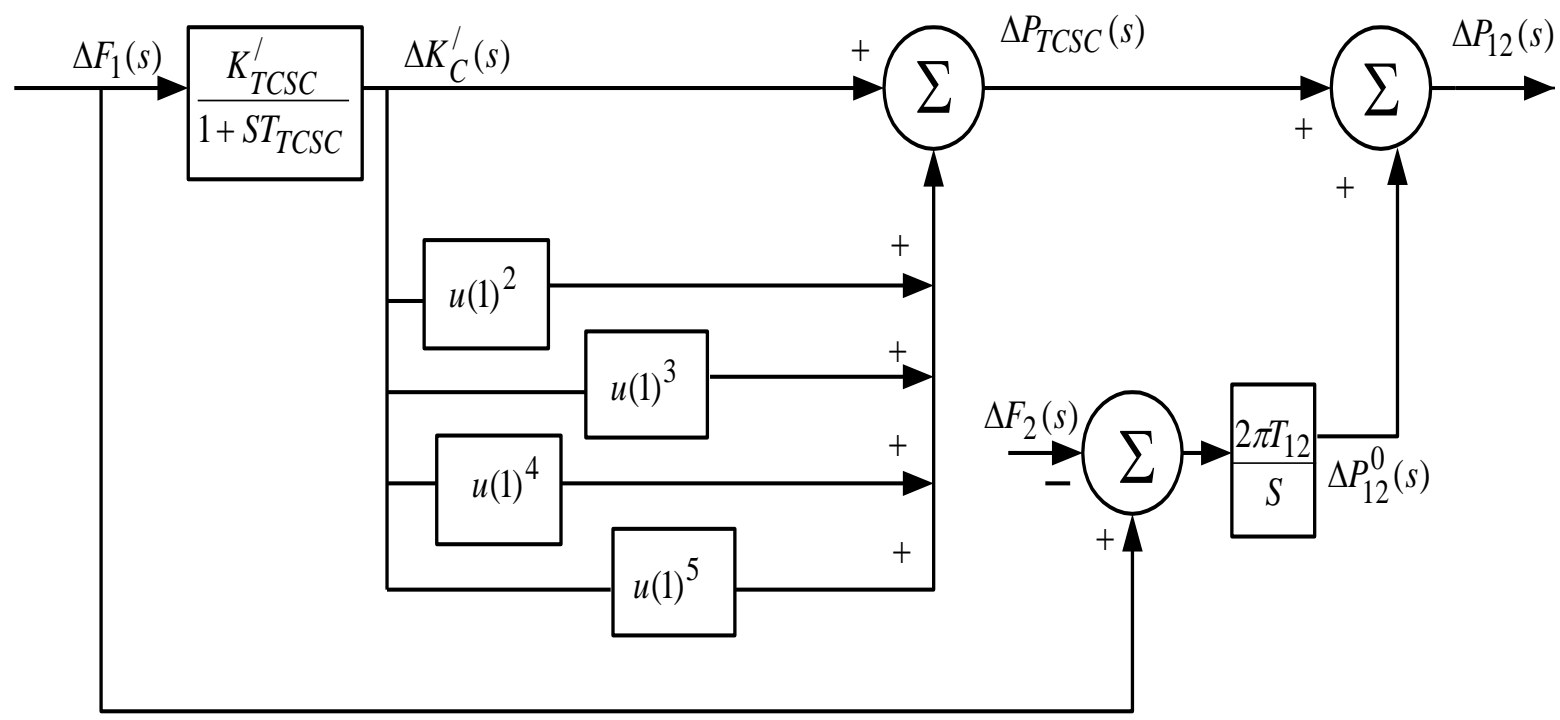

Fig. 2 Basic structure for the proposed TCSC-based damping controller

From the Taylor series expansion method, we know that for $|x|<1$ :

$$
\frac{1}{1-x}=1+x+x^{2}+x^{3}+x^{4}+\ldots \ldots
$$

As the compensation ratio is bound in the range $(-1,1)$ i.e. $\left|\Delta k_{C}\right|<1$ for both inductive and capacitive operation modes, the above Taylor series expansion can be used to model TCSC controller as follows

$$
\frac{\Delta k_{C}}{1-\Delta k_{C}}=\Delta k_{C}+\Delta k_{C}{ }^{2}+\Delta k_{C}{ }^{3}+\Delta k_{C}{ }^{4}+\Delta k_{C}{ }^{5}+\ldots \ldots
$$

Hence Eq. (10) can be written as:

$$
\begin{aligned}
& \Delta P_{T i e 12}(s)=\frac{2 \pi T_{12}}{S}\left[\Delta F_{1}(s)-\Delta F_{2}(s)\right]+\left(\Delta k_{C}+\Delta k_{C}{ }^{2}+\right. \\
& \left.\Delta k_{C}{ }^{3}+\Delta k_{C}{ }^{4}+\Delta k_{C}{ }^{5}+\ldots \ldots . .\right) K_{1}
\end{aligned}
$$

From equation (12), the tie-line power flow can be regulated by controlling $\Delta \mathrm{k}_{\mathrm{C}}$ (s). If the control input signal to TCSC damping controller is assumed to be $\Delta$ Error (s) and the transfer function of the signal conditioning circuit

$$
\begin{aligned}
& k_{c}=\frac{K_{T C S C}}{1+s T_{T C S C}} \text {, the expression is given in } \\
& \text { is } \\
& \Delta k_{C}(s)=\frac{K_{T C S C}}{1+s T_{T C S C}} \Delta \operatorname{Eror}(s)
\end{aligned}
$$

Where $\mathrm{K}_{\mathrm{TCSC}}$ and $\mathrm{T}_{\mathrm{TCSC}}$ is the gain and time constant of the TCSC controller respectively. The basic structure of proposed TCSC-based controller is shown in Fig. 2 where the frequency deviation in area 1 i.e. $\Delta \mathrm{F}_{1}$ may be suitably used as the control signal $\Delta$ Error(s), to the TCSC unit to control the percentage incremental change in the system compensation level. Therefore,

$\Delta k_{C}(s)=\frac{K_{T C S C}}{1+s T_{T C S C}} \Delta F_{1}(s)$

According to the design objectives, only the first five terms in (13) are used in TCSC controller designed as shown in Fig. 2. In the proposed TCSC controller, $K_{1}$ is included in the TCSC gain $K_{T C S C}$ i.e. $K_{T C S C}^{\prime}=K_{T C S C} \cdot K_{1}$ in which

$$
\begin{aligned}
& \Delta P_{T C S C}=\Delta K_{C}^{\prime}+\left(\Delta K_{C}^{\prime}\right)^{2}+\left(\Delta K_{C}^{\prime}\right)^{3}+\left(\Delta K_{C}^{\prime}\right)^{4}+\left(\Delta K_{C}^{\prime}\right)^{5} \\
& \qquad \Delta K_{C}^{\prime}=\frac{K_{T C S C}^{\prime}}{1+S T_{T C S C}} \Delta F_{1}(s) \\
& \text { Where }
\end{aligned}
$$

\section{Control structure and Objective function}

To control the frequency of each area, The TIDF controllers are provided in each area as it offers simpler tuning, better disturbance rejection ratio, and have less effects of plant parameter variations on closed loop response. The TIDF controller designing and tuning is not only easy than PID but also faster. TIDF control is robust, and its transient response to command input ratio remains good over a wider range of plant parameter variation. The design of TIDF controller is similar to that of PIDF controller, but only difference is that the proportional component of the compensator is replaced with tilted component having transfer function $s$ to the power of $-1 / n$. The structure of TIDF controller is shown in Fig.3, where $\mathrm{K}_{\mathrm{P}}, \mathrm{K}_{\mathrm{D}}, \mathrm{K}_{\mathrm{I}}, \mathrm{n}$ are proportional, derivative, integral gains and $\mathrm{n}$ is a nonzero real number respectively [6].

In the design of a modern heuristic optimization technique based controller, the objective function is first defined based on the desired specifications and constraints. 


\section{ISO 3297:2007 Certified}

Vol. 5, Issue 3, March 2017

Performance criteria usually considered in the control design are the Integral of Time multiplied Absolute Error (ITAE), Integral of Squared Error (ISE), Integral of Time multiplied Squared Error (ITSE) and Integral of Absolute Error (IAE). ITAE criterion reduces the settling time which cannot be achieved with IAE or ISE based tuning.

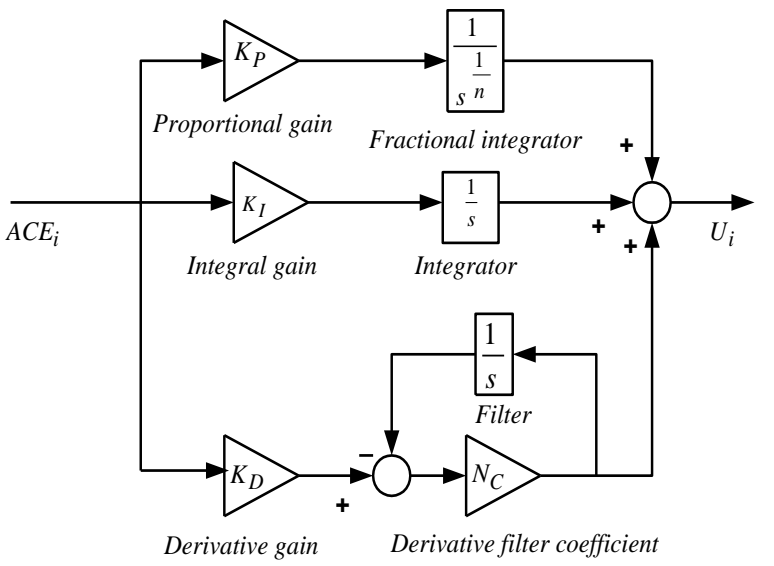

Fig.3 Structure of TIDF controller

ITAE criterion also reduces the peak overshoot. ITSE based controller provides large controller output for a sudden change in set point which is not advantageous from controller design point of view. It has been reported that ITAE is a better objective function in LFC studies [7]. Therefore in this paper ITAE is used as objective function to optimize the scaling factors and proportional, integral and derivative gains of DE TIDF controller. Expression for the ITAE objective function is depicted in equation (18).

$$
J=I T A E=\int_{0}^{t_{\text {sim }}}\left(\left|\Delta f_{1}\right|+\left|\Delta f_{2}\right|+\left|\Delta P_{\text {Tie }}\right|\right) \cdot t \cdot d t
$$

In the above equations, $\Delta f_{1}$ and $\Delta f_{2}$ are the system frequency deviations; $\Delta P_{\text {Tie }}$ is the incremental change in tie line power; $t_{\text {sim }}$ is the time range of simulation.

\section{III.OVER VIEW OF DE ALGORITHM}

Differential Evolution (DE) algorithm is a heuristic search algorithm introduced by Storn and Price [6]. It is a simple, efficient, reliable algorithm with easy coding. The main advantage of DE over Genetic Algorithm (GA) is that GA uses crossover operator for evolution, while DE relies on mutation operation based on the difference of randomly sampled pairs of solutions in the population. An optimization task consisting of $\mathrm{D}$ variables can be represented by a D-dimensional vector. At the beginning a population of $\mathrm{N}_{P}$ solution vectors is randomly initialized within the parameter bounds. The population is then modified by applying mutation, crossover and selection operators. DE algorithm uses two generations; one is old generation and the other one is new generation of the same population size. Individuals of the current population become target vectors for the next generation. The mutation operation produces a mutant vector for each target vector which is obtained by adding the weighted difference between two randomly chosen vectors to a third vector. The crossover operation generates a trail vector by mixing the parameters of the mutant vector with those of the target vector. The trial vector first tries to obtain a better fitness value than the target vector and then it substitutes the target vector in the next generation. The evolutionary operators are described below [8-10]:

\section{A. Initialization of parameter}

DE begins with a randomly initiated population of size $N_{P}$ of $\mathrm{D}$ dimensional real-valued parameter vectors. Each parameter $j$ lies within a range and the initial population should spread over this range as much as possible by uniformly randomizing individuals within the search space constrained by the prescribed lower bound $X_{j}^{L}$ and upper bound $X_{j}^{U}$.

\section{B. Mutation operation}

For the mutation operation, a parent vector from the current generation is selected (known as target vector), a mutant vector is obtained by the differential mutation operation (known as donor vector) and finally an offspring is produced by combining the donor with the target vector (known as trial vector). Mathematically it can be expressed as:

$$
V_{i, G+1}=X_{r 1, G}+F \cdot\left(X_{r 2, G}-X_{r 3, G}\right)
$$

Where $X_{i, G}$ is the given parameter vector, $X_{r 1, G}$ $X_{r 2, G} X_{r 3, G}$ are randomly selected vector with distinct indices $i, r 1, r 2$ and $r 3, V_{i, G+1}$ is the donor vector and $\mathrm{F}$ is a constant from $(0,2)$.

TABLE I. Optimal Gain Values

\begin{tabular}{|l|l|l|}
\hline $\begin{array}{l}\text { Controller/ } \\
\text { Parameters }\end{array}$ & Only TIDF & $\begin{array}{l}\text { TIDF with } \\
\text { TCSC }\end{array}$ \\
\hline $\mathrm{KP}$ & 1.4073 & 1.8825 \\
\hline $\mathrm{KI}$ & 1.8379 & 1.9917 \\
\hline $\mathrm{KD}$ & 1.3201 & 1.5716 \\
\hline $\mathrm{n}$ & 8.4883 & 8.6216 \\
\hline $\mathrm{N}_{\mathrm{C}}$ & 246.3908 & 265.5285 \\
\hline $\mathrm{K}_{\mathrm{TCSC}}$ & $\ldots \ldots .$. & 0.0352 \\
\hline $\mathrm{T}_{\mathrm{TCSC}}$ & $\ldots \ldots \ldots$ & 0.0048 \\
\hline
\end{tabular}

\section{Crossover operation}

After generating the donor vector through mutation the crossover operation is employed to enhance the potential diversity of the population. For crossover operation three parents are selected and the child is obtained by means of 


\section{ISO 3297:2007 Certified}

Vol. 5, Issue 3, March 2017

perturbation of one of them. In crossover operation a trial vector $U_{i, G+1}$ is obtained from target vector $\left(X_{i, G}\right)$ and donor vector $\left(V_{i, G}\right)$. The donor vector enters the trial vector with probability $\mathrm{CR}$ given by:

$$
U_{j, i, G+1}=\left\{\begin{array}{l}
V_{j, i, G+1} \quad \text { if } \quad \text { rand }_{j, i} \leq C R \quad \text { or } \quad j=I_{\text {rand }} \\
X_{j, i, G+1} \quad \text { if } \quad \text { rand }_{j, i}>C R \quad \text { or } j \neq I_{\text {rand }}
\end{array}\right.
$$

With rand $_{j, i} \sim U(0,1), I_{\text {rand }}$ is a random integer from $(1,2, \ldots . D)$ where $D$ is the solution's dimension i.e. number of control variables. $I_{\text {rand }}$ ensures that $V_{i, G+1} \neq X_{i, G}$.

D. Selection operation

To keep the population size constant over subsequent generations, selection operation is performed. In this operation the target vector $X_{i, G}$ is compared with the trial vector $V_{i, G+1}$ and the one with the better fitness value is admitted to the next generation. The selection operation in DE can be represented by:

$$
X_{i, G+1}= \begin{cases}U_{i, G+1} & \text { if } f\left(U_{i, G+1}\right)<f\left(X_{i, G}\right) \\ X_{i, G} & \text { otherwise. }\end{cases}
$$

where $i \in\left[1, N_{P}\right]$.

TABLE II. Optimal Gain Values

\begin{tabular}{|c|c|c|c|}
\hline \multicolumn{2}{|c|}{ Controller } & $\begin{array}{l}\text { DE- } \\
\text { Tuned } \\
\text { TIDF }\end{array}$ & $\begin{array}{l}\text { DE-Tuned } \\
\text { TIDF- } \\
\text { TCSC }\end{array}$ \\
\hline \multirow{2}{*}{$\begin{array}{c}\text { Peak } \\
\text { overshoot } \\
* \mathbf{1 0}^{-3}\end{array}$} & ITAE & $\mathbf{0 . 2 3 2 8}$ & $\mathbf{0 . 2 0 1 5}$ \\
\cline { 2 - 4 } & $\Delta \mathrm{F}_{1}$ & 0.0033 & 0.0015 \\
\cline { 2 - 4 } & $\Delta \mathrm{F}_{2}$ & 0.0010 & 0.0001 \\
\cline { 2 - 4 } & $\Delta \mathrm{P}_{\text {Tie }}$ & 0.0003 & 0.0000 \\
\hline \multirow{2}{*}{$\begin{array}{c}\text { Peak } \\
\text { undershoot } \\
* \mathbf{1 0}^{-3}\end{array}$} & $\Delta \mathrm{F}_{1}$ & -0.0670 & -0.0569 \\
\cline { 2 - 4 } & $\Delta \mathrm{F}_{2}$ & -0.0340 & -0.0284 \\
\cline { 2 - 4 } & $\Delta \mathrm{P}_{\text {Tie }}$ & -0.0135 & -0.0114 \\
\hline
\end{tabular}

\section{IV.SIMULATION RESULTS}

The usefulness of proposed controller was demonstrated by considering three cases. In the first case $10 \%$ step load is applied to area 1 only, In the second case $10 \%$ step load is applied to area 2 only, finally $10 \%$ and $20 \%$ step load is applied to area 1 and area 2 respectively which is depicted in case 3. DE algorithm has been used to optimize the controller coefficients. The optimization was repeated 50 times and the best final solution among the 50 runs is chosen as proposed controller parameters. The optimum values of the different controllers are given in Table I.
Initially $10 \%$ of load disturbance is applied in area 1 to investigate the performance of the system with proposed system. The dynamic performance of the system are shown in the Figs. 4-6.The corresponding performance index in terms of ITAE value, peak overshoot, peak undershoot and tie line power deviations is shown in Table II.

TABLE III. Optimal Gain Values

\begin{tabular}{|c|c|c|c|}
\hline \multicolumn{2}{|c|}{ Controller } & $\begin{array}{l}\text { DE- } \\
\text { Tuned } \\
\text { TIDF }\end{array}$ & $\begin{array}{l}\text { DE-Tuned } \\
\text { TIDF- } \\
\text { TCSC }\end{array}$ \\
\hline $\begin{array}{c}\text { Peak } \\
\text { overshoot } \\
* \mathbf{1 0}^{-3}\end{array}$ & ITAE & $\mathbf{0 . 2 3 2 8}$ & $\mathbf{0 . 2 0 6 4}$ \\
\cline { 2 - 4 } & $\Delta \mathrm{F}_{1}$ & 0.0010 & 0.0001 \\
\cline { 2 - 4 } & $\Delta \mathrm{F}_{2}$ & 0.0033 & 0.0018 \\
\cline { 2 - 4 } & $\Delta \mathrm{P}_{\mathrm{Tie}}$ & 0.0135 & 0.0113 \\
\hline \multirow{2}{*}{$\begin{array}{c}\text { Peak } \\
\text { undershoot } \\
* \mathbf{1 0}^{-3}\end{array}$} & $\Delta \mathrm{F}_{1}$ & -0.0340 & -0.0283 \\
\cline { 2 - 4 } & $\Delta \mathrm{F}_{2}$ & -0.0670 & -0.0603 \\
\cline { 2 - 4 } & $\Delta \mathrm{P}_{\mathrm{Tie}}$ & -0.0003 & -0.0000 \\
\hline
\end{tabular}

Further to demonstrate the effectiveness of TIDF controller a step load of $10 \%$ applied to area-2 only. The dynamic performance of the system is shown in Fig. 7-9. The corresponding performance index in terms of ITAE value, peak overshoot, peak undershoot and tie line power deviations is shown in Table III.

Finally load is applied to both the areas i.e. $10 \%$ and $20 \%$ respectively, whose dynamic response are shown in Fig. 10-12. The corresponding performance index in terms of ITAE value, peak overshoot, peak undershoot and tie line power deviations is shown in Table IV.

TABLE IV. Optimal Gain Values

\begin{tabular}{|c|c|c|c|}
\hline \multicolumn{2}{|c|}{ Controller } & $\begin{array}{l}\text { DE- } \\
\text { Tuned } \\
\text { TIDF }\end{array}$ & $\begin{array}{l}\text { DE-Tuned } \\
\text { TIDF- } \\
\text { TCSC }\end{array}$ \\
\hline \multirow{2}{*}{$\begin{array}{c}\text { Peak } \\
\text { overshoot } \\
* \mathbf{1 0}^{-3}\end{array}$} & ITAE & $\mathbf{0 . 5 7 5 0}$ & $\mathbf{0 . 5 0 5 9}$ \\
\cline { 2 - 4 } & $\Delta \mathrm{F}_{1}$ & 0.0039 & 0.0007 \\
\cline { 2 - 4 } & $\Delta \mathrm{F}_{2}$ & 0.0060 & 0.0023 \\
\cline { 2 - 4 } & $\Delta \mathrm{P}_{\text {Tie }}$ & 0.0135 & 0.0113 \\
\hline \multirow{2}{*}{$\begin{array}{c}\text { Peak } \\
\text { undershoot } \\
* \mathbf{1 0}^{-3}\end{array}$} & $\Delta \mathrm{F}_{1}$ & -0.1050 & -0.0872 \\
\cline { 2 - 4 } & $\Delta \mathrm{F}_{2}$ & -0.1397 & -0.1286 \\
\cline { 2 - 4 } & $\Delta \mathrm{P}_{\text {Tie }}$ & -0.0003 & -0.0003 \\
\hline
\end{tabular}

From the Fig. 4-12 it is revels that TIDF controller performs satisfactorily for same optimal gain values. These simulations are carried out while TCSC unit is present in tie-line of two area power system and without TCSC unit in tie-line. The simulations show the positive effect of TCSC unit on the improvement of the oscillation of frequency due to any load perturbation. the dynamic response is shown in Figs 4-12. From the dynamic response it is revels that the proposed TIDF controller with TCSC gives better response. 
Vol. 5, Issue 3, March 2017

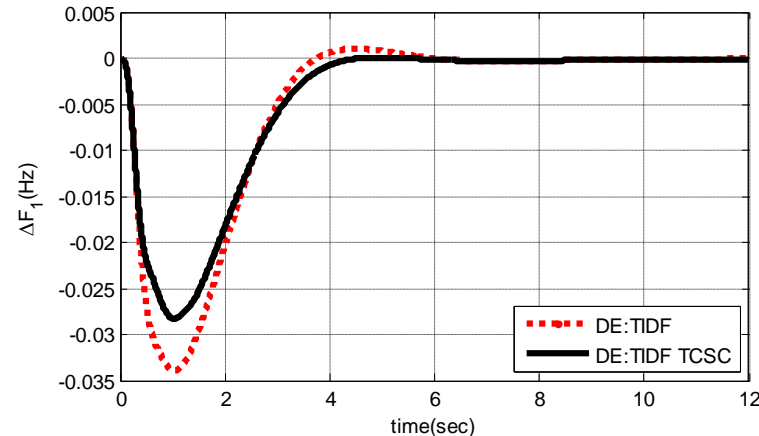

Fig.4 Change in frequency of area-1 for 0.1 p.u. change in area-1

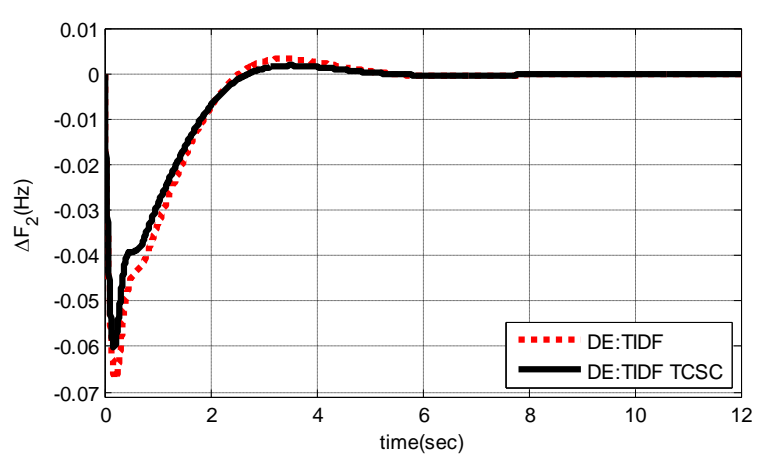

Fig.5 Change in frequency of area- 2 for 0.1 p.u. change in area-1

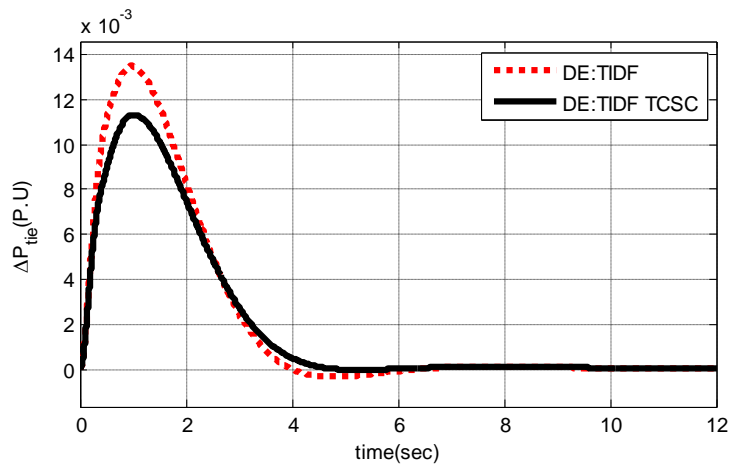

Fig.6 Change in tie line power for 0.1 p.u. change in area1.

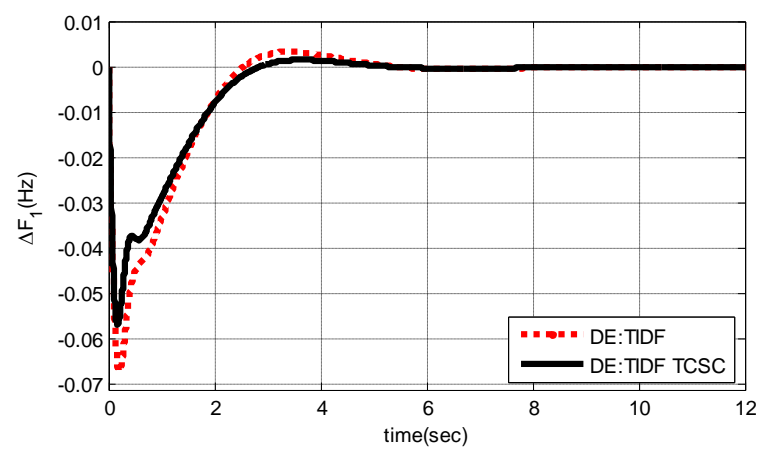

Fig.7 Change in frequency of area- 1 for 0.1 p.u. change in area-2

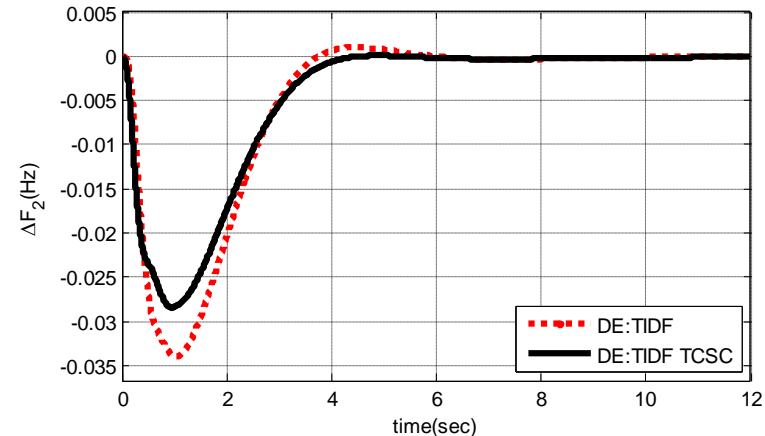

Fig.8 Change in frequency of area- 2 for 0.1 p.u. change in area-2

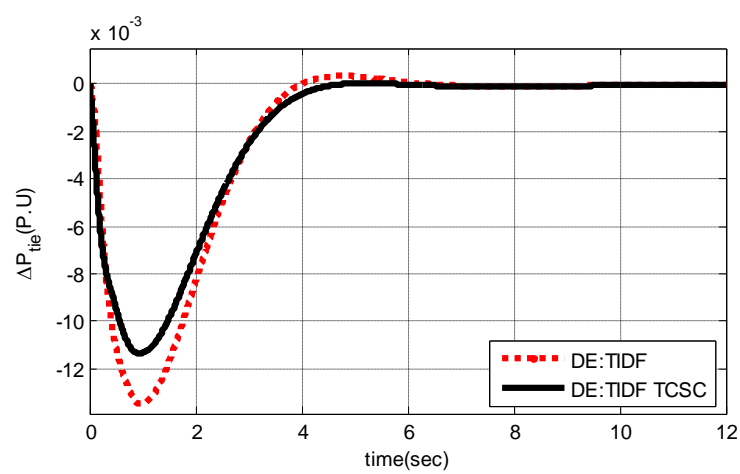

Fig.9 Change in tie line power for 0.1 p.u. change in area2.

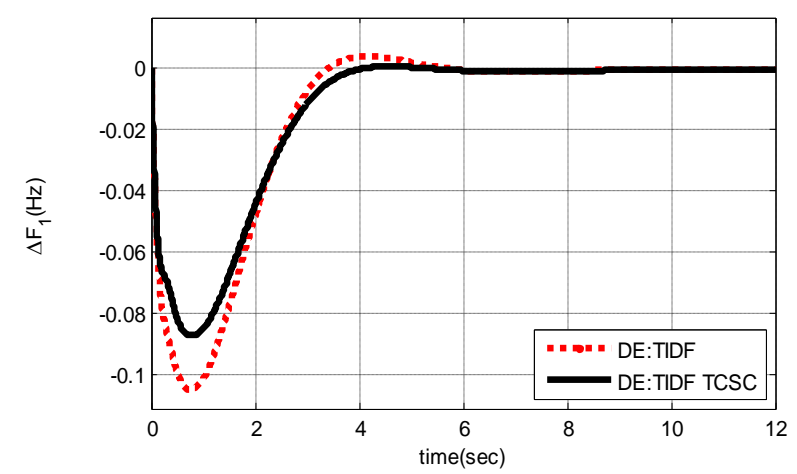

Fig.10 Change in frequency of area-1 for 0.1 p.u. change in area- 1 and 0.2 p.u. change in area- 2

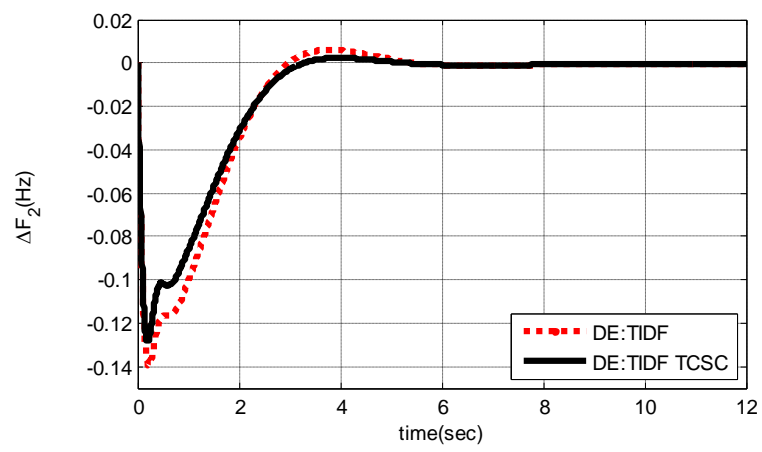

Fig.11 Change in frequency of area-2 for 0.1 p.u. change in area- 1 and 0.2 p.u. change in area- 2 
Vol. 5, Issue 3, March 2017

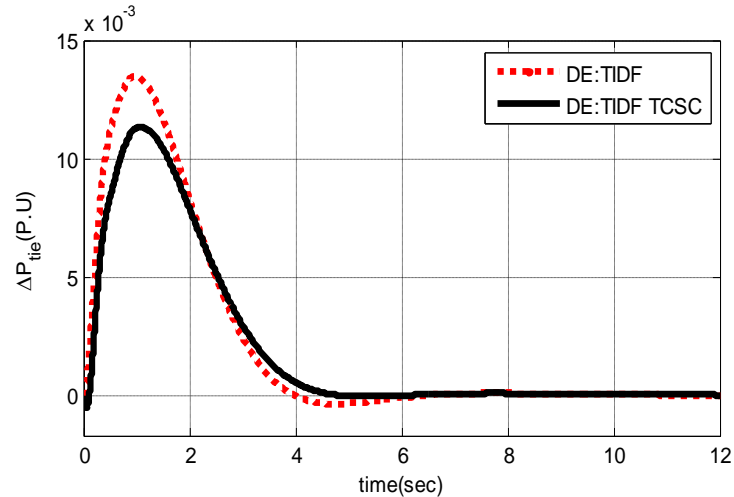

Fig.12 Change in tie line power for 0.1 p.u. change in area- 1 and 0.2 p.u. change in area- 2

\section{CONCLUSION}

In this paper, Differential Evolution (DE) is proposed to tune the controller parameters for Load Frequency Control (LFC) problem. The superiority of the proposed design approach has been shown by comparing the results with TIDF controller without TCSC and TIDF controller with TCSC. Investigations reveal that TIDF controller with TCSC provides better dynamics than TIDF controller without TCSC. it is observed that significant improvements of dynamic performance of the system in terms Integral of Time multiplied by Absolute value of Error (ITAE), peak overshoot and peak undershoot are obtained with TIDF controller with TCSC.

\section{ACKNOWLEDGMENT}

The authors gratefully acknowledge the contributions of the Department of Electrical Engineering, IGIT, Sarang and Department of Electrical Engineering, IGIT, Sarang for their work on the original version of this document.

\section{APPENDIX}

Nominal Parameters of the Power System [5]

$\mathrm{B}_{1}=\mathrm{B}_{2}=0.425 \mathrm{pu} \mathrm{MW} / \mathrm{Hz} ; \mathrm{R}_{1}=\mathrm{R}_{2}=2.4 \mathrm{~Hz} /$ p.u.; $\mathrm{T}_{\mathrm{G} 1}=$ $\mathrm{T}_{\mathrm{G} 1}=0.08 \mathrm{sec}, \mathrm{T}_{\mathrm{T} 1}=\mathrm{T}_{\mathrm{T} 2}=0.3 \mathrm{~s} ; \mathrm{T}_{\mathrm{R} 1}=\mathrm{T}_{\mathrm{R} 2}=10 \mathrm{~s} ; \mathrm{K}_{\mathrm{PS} 1}=$ $\mathrm{K}_{\mathrm{PS} 2}=$

$120 \mathrm{~Hz} /$ p.u. $\mathrm{MW} ; \mathrm{T}_{\mathrm{PS} 1}=\mathrm{T}_{\mathrm{PS} 2}=20 \mathrm{~s} ; \mathrm{T}_{12}=0.545, \mathrm{a}_{12}=-1$.

\section{REFERENCES}

[1] D.P. Kothari and I.J. Nagrath, Modern Power System Analysis,3rd ed, Singapore, McGraw Hill, 2003.

[2] Elgerd, OI. Electric Energy Systems Theory - An Introduction, New Delhi: Tata McGraw Hill, 2000.

[3] N. Jaleeli, D.N. Ewart, and L.H. Fink, "Understanding Automatic Generation Control," IEEE Transactions on Power System, vol. 7, No. 3, pp. 1106- 1122, August 1992.

[4] N. G. Hingorani and L. Gyugyi, Understanding FACTS: concepts andtechnology of flexible AC transmission systems, IEEE Press, NewYork,2000.

[5] U.K Rout, R.K. Sahu, and S. Panda, "Design and analysis of differential evolution algorithm based automatic generation control

for interconnected power system," Ain Shams Eng. J., Vol. 4, No. 3, pp. 409-421, 2013.

[6] B. J. Lurie, "Three-parameter tunable tilt-integral derivative (TID) controller,'US Patent US5371670, 1994.

[7] R.K Sahu, S. Panda, A Biswal, G. T Chandra Sekhar "Design and analysis of tilt integral derivative controller with filter for load frequency control of multi area interconnected power system," ISA Transations Elsevier, Article in press.

[8] R. Stron and K. Price, "Differential evolution - a simple and efficient adaptive scheme for global optimization over continuous spaces," J Glob Optim 1995;11:341-59

[9] S. Padhan, R.K. Sahu and S. Panda, “Application of Firefly Algorithm for Load Frequency Control of Multi-area Interconnected Power System,'Electric Power Components and Systems, vol. 42, pp. 1419-1430. 2014.

[10] R. Stron and K. Price, "Differential evolution - a simple and efficient adaptive scheme for global optimization over continuous spaces," J Glob Optim 1995;11:341-59

\section{BIOGRAPHIES}

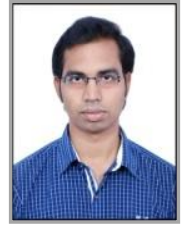

Odisha, India

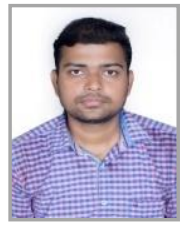

Ashutosh Biswal was born in India in 1991 and is a citizen of India; He received the B. Tech degree in Electrical Engineering in 2012 and M. Tech degree from VSSUT, Burla, Odisha, India in 2015. Currently he is working as Assistant Professor (consolidated), Department of Electrical Engineering, in Indira Gandhi Institute of Technology, Sarang. His areas of Interest are Power system operation and control, Power electronics and Drives. 1992 and is a citizen of India; He received B.Tech. degree in Electrical in 2013 and currently pursuing for M.Tech degree from Indira Gandhi Institute of Technology, Sarang, affiliated to BPUT, Rourkela,

Sarada Prasanna Behera was born in . 